\title{
Stress-Rupture Characterization in Nickel-Based Superalloy Gas Turbine Engine Components
}

\author{
Wesley D. Pridemore
}

Published online: 15 August 2008

(C) ASM International 2008

\section{Erratum to: J Fail. Anal. and Preven.}

\section{DOI 10.1007/s11668-008-9140-y}

Due to a publication error, Figure 15 was published with the labels switched for the two micrographs. We apologize for this error, and print the corrected Figure 15 below.

Fig. 15 Effect of hightemperature exposure resulting in partial resolutioning of the gamma prime $\left(\gamma^{\prime}\right)$ precipitates in a SX blade casting. Rafting (coalescence and elongation of the $\gamma^{\prime}$ ) occurs perpendicular to the primary stress direction. Cuboidal precipitates (darker phase) is $\gamma^{\prime}$. Matrix is the lighter $\gamma$ phase. Etchant: $33 \%$ glycerol, $33 \%$ nitric acid, $33 \%$ acetic acid, and $1-3 \%$ hydrofluoric acid

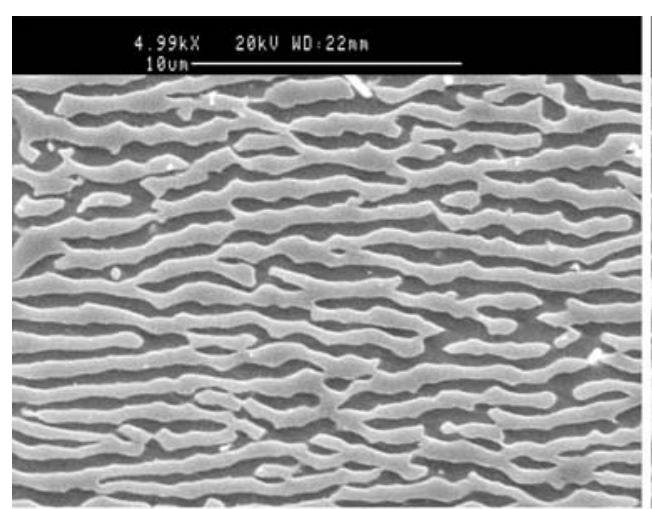

Gamma Prime ( $\left.\gamma^{\prime}\right)$ Structure @ 5\% TE Airfoil Span Partially Resolutioned, Rafted $\gamma$ ' Structure

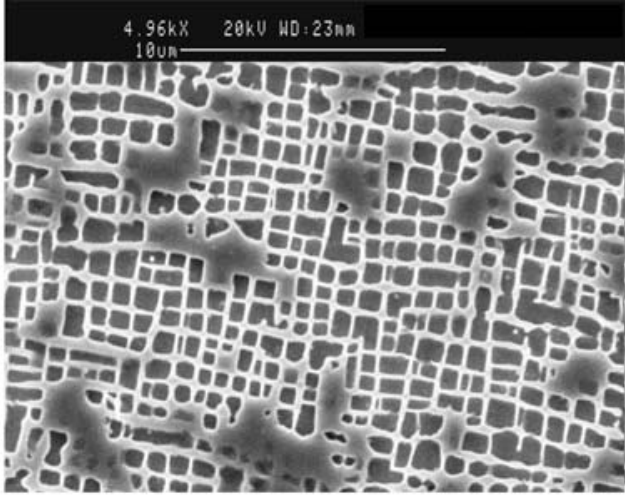

Non-Heat Distressed Cuboidal Gamma Prime $\left(\gamma^{\prime}\right)$ Structure

The online version of the original article can be found under doi:10.1007/s11668-008-9140-y.

W. D. Pridemore $(\bowtie)$

Failure Analysis, Materials, Processes and Engineering

Department, GE Aviation, Cincinnati, OH, USA

e-mail: doug.pridemore@ae.ge.com 